\title{
Les Visions de Quevedo, traduites par le Sieur de la Geneste, édition, introduction et notes par Marie Roig Miranda
}

\section{Monica Pavesio}

\section{(2) OpenEdition}

\section{Journals}

\section{Edizione digitale}

URL: http://journals.openedition.org/studifrancesi/36021

DOI: $10.4000 /$ studifrancesi.36021

ISSN: 2421-5856

\section{Editore}

Rosenberg \& Sellier

\section{Edizione cartacea}

Data di pubblicazione: 1 juillet 2005

Paginazione: 154

ISSN: 0039-2944

\section{Notizia bibliografica digitale}

Monica Pavesio, «Les Visions de Quevedo, traduites par le Sieur de la Geneste, édition, introduction et notes par Marie Roig Miranda», Studi Francesi [Online], 145 (XLIX | I) | 2005, online dal 30 novembre 2015, consultato il 18 avril 2021. URL: http://journals.openedition.org/studifrancesi/36021 ; DOI: https://doi.org/10.4000/studifrancesi.36021

Questo documento è stato generato automaticamente il 18 avril 2021.

\section{cc) (†) $\odot$}

Studi Francesi è distribuita con Licenza Creative Commons Attribuzione - Non commerciale - Non opere derivate 4.0 Internazionale. 


\title{
Les Visions de Quevedo, traduites par le Sieur de la Geneste, édition, introduction et notes par Marie Roig Miranda
}

\author{
Monica Pavesio
}

\section{NOTIZIA}

Les Visions de Quevedo, traduites par le Sieur de la Geneste, édition, introduction et notes par Marie ROIG MIRANDA, Paris, Champion, 2004, pp. 492.

1 Les Visions de Quevedo, pubblicate a Parigi nel 1632 da uno scrittore ancora oggi sconosciuto che si firma con lo pseudonimo di Sieur de la Geneste, sono la prima traduzione francese dei cinque Sueños del poeta spagnolo Francisco de Quevedo e di una sesta opera, La Casa de los locos de amor, contenuta in alcune edizioni dei Sueños anche se non appartenente all'autore spagnolo. Due anni dopo, de la Geneste pubblicò una seconda edizione della sua traduzione con l'aggiunta di una settima Vision, tratta da un'altra opera di Quevedo il Discurso de todos los diablos.

2 Da questa data in poi, le Visions di de la Geneste, pubblicate con quest'ultima opera che prese il titolo francese di L'Enfer reformé, ebbero un tale successo in Francia (più di cento edizioni in meno di cento anni) ed in Italia, Olanda, Germania ed Inghilterra, dove furono pubblicate più volte a partire dall'edizione francese di de la Geneste.

3 L'edizione curata da Marie Roig Miranda di quest'opera capitale per lo studio della letteratura francese del XVII e XVIII secolo è corredata da un ricco apparato di note e da un'interessante introduzione. Dopo essersi soffermata a lungo sullo studio dei Sueños di Quevedo e sulla traduzione di de la Geneste, la curatrice mette a confronto le due opere analizzando accuratamente le aggiunte, i tagli, le omissioni, le semplificazioni che l'autore francese apporta al testo spagnolo. Ricerca poi le tracce dei Sueños e delle 
Visions nei testi letterari francesi del XVII e XVIII secolo, per evidenziare l'importanza dell'opera di Quevedo nel panorama letterario dell'epoca.

4 Un successo straordinario quello ottenuto dai Suenos e dalle Visions, che emerge dalla ricca bibliografia che conclude il volume, comprendente oltre alle opere critiche generali, le edizioni dei Sueños, delle Visions di de la Geneste (circa un centinaio repertoriate con le relative collocazioni nelle biblioteche europee), delle traduzioni successive di Raclots e di Dom Galeo, delle traduzioni inglesi, olandesi, tedesche, italiane e latine. 